\title{
Proton adsorption mechanism at the gibbsite and aluminium oxide solid/solution interface
}

\author{
T. Hiemstra, W. H. van Riemsdijk and M. G. M. Bruggenwert \\ Department of Soil Science and Plant Nutrition, Wageningen Agricultural Univer- \\ sity, P.O.Box 8005, NL 6700 EC Wageningen, Netherlands
}

Received 16 April 1987; accepted 15 June 1987

Key words: aluminium hydroxide, gibbsite, aluminium oxide, singly coordinated surface hydroxyl, doubly coordinated surface hydroxyl, proton adsorption, variable charge, one-pK model, pair formation, site density, site distribution, back titration method

\begin{abstract}
Titration curves of a synthetic pure crystalline gibbsite suspension have been made at three $\mathrm{NaCl}$ levels. The synthesized gibbsite is characterized by TEM, TGA and $\mathrm{X}$-ray diffraction. The overall BET surface area and the surface area of the edges of the hexagonal crystals are determined. The surface structure of gibbsite is discussed. The $\sigma_{0}-\mathrm{pH}$ data are analysed with a recently proposed one-step charging model for proton adsorption (one-pK model). Analysis of the data suggests that the singly coordinated surface hydroxyls are probably the dominant reactive surface group. Considering these groups as reactive only the titration data could be fitted well with the one-pK model if it is extended with pair formation. Only two adjustable parameters are needed, the Stern layer capacitance and the pair formation constant. Analysis of titration data of aluminium oxides, as presented in recent literature, showed that all $\sigma_{0}$ - $\mathrm{pH}$ curves could be described rather well with one and the same set of two parameters, the capacitance of the Stern layer and the pair formation constant. The difference in proton adsorption behaviour between different aluminium (hydr)oxides is mainly caused by differences in the site distribution and the site densities of the aluminium (hydr)oxides involved. The results suggest that pair formation should be taken into account.
\end{abstract}

\section{Introduction}

Hydroxides of aluminium are frequently found in soils as independent particles or as coatings on soil minerals. Gibbsite can be seen as the crystalline representative of this important group of aluminium hydroxides.

The proton adsorption studies of gibbsite are scarce which is probably due to the 
difficulties of the preparation of sufficiently concentrated pure crystalline suspensions and the higher solubility compared with other model oxides such as ferric oxides, limiting the $\mathrm{pH}$ range of the titrations. The surface of aluminium hydroxide is amphoteric and the behaviour of its reactive groups is of importance with respect to adsorption studies of many chemical species. Recently some attempts have been made to connect variable charge characteristics with the dissolution behaviour of aluminium (hydr)oxides (Pulver et al., 1984; Furrer \& Stumm, 1986). In such a case extrapolation of titration curves from the $\mathrm{pH}$ range of the titration to the $\mathrm{pH}$ range of dissolution is desirable, but this is only justified if sufficient certainty exists about the correctness in the extrapolation of the model involved. At high proton adsorption levels at low $\mathrm{pH}$, the degree of surface saturation is strongly determined by the reactive site density. This site density is an important parameter in the available proton adsorption models. This study will evaluate the role of the distribution of reactive sites and the site density in the description of the charging behaviour of aluminium (hydr)oxides.

Due to its morphology gibbsite crystals have two types of crystal surfaces which are clearly spatially separated. Both surfaces possess a different type of adsorption sites which may have a different affinity for protons. Well defined gibbsite crystals make it possible to determine the site density and the number of sites of the surface groups involved. This study intends to contribute to the understanding of the proton adsorption behaviour of these two types on surface groups exposed.

Analysis of $\sigma_{0}-\mathrm{pH}$ data is done on the basis of a proton adsorption model for metal oxides which is partially based on crystallographic considerations (Bolt \& van Riemsdijk, 1982). This one-step charging model is considered as the simplest, physically realistic model for proton adsorption at the aluminium (hydr)oxide solid/solution interface.

\section{Experimental}

Gibbsite suspensions were prepared according to Gastuche \& Herbillon (1962). Aluminium chloride solution $(0.33 \mathrm{M})$ was slowly titrated with $\mathrm{NaOH}(1.0 \mathrm{M})$ to a $\mathrm{pH}$ of 4.5 resulting in a partially neutralized suspension which was subsequently dialysed at $70{ }^{\circ} \mathrm{C}$ during four weeks against double-distilled water which was refreshed twice a day. This procedure leads to the formation of well crystallized gibbsite particles. Finally, the suspension was concentrated by flocculation at $\mathrm{pH} 8$ in 1 $\mathrm{M} \mathrm{NaCl}$ followed by a second dialysis. The suspension was stored at $4{ }^{\circ} \mathrm{C}$ during 5 years. The final $\mathrm{pH}$ of the salt-free suspension was about 5.3.

The titration experiments carried out between $\mathrm{pH} 4.5$ and 9.5 were performed at constant temperature of $20 \pm 0.1{ }^{\circ} \mathrm{C}$. A volume of $50 \mathrm{ml}$ of the concentrated suspension $\left(37 \mathrm{~g} \mathrm{~kg}^{-1}\right)$ was pipetted together with $1 \mathrm{ml}$ electrolyte $(\mathrm{NaCl})$ into a vessel. Purified, moist $\mathrm{N}_{2}$ gas was led over the suspension in the closed vessel during a few hours until the $\mathrm{pH}$ was stabilized $(\mathrm{pH} 7.7)$. For each electrolyte level a forward and a backward titration with, respectively, acid and base was performed. Due to the high point of zero charge (PZC) of gibbsite it was possible to keep the electrolyte concentration constant during the titration experiments by using acid and base solu- 
tions having a sodium concentration equal to the concentration level of $\mathrm{NaCl}$ in the titration cell. The acid and base solutions were made from mixtures of $\mathrm{NaCl}$ with acid $(\mathrm{HCl})$ or base $(\mathrm{NaOH})$. All solutions were prepared with outgased water. Acid and base were added with microburets of $5 \mathrm{ml}$. The change of salt level was carried out at low $\mathrm{pH}(\mathrm{pH} 5)$ by pipetting the appropriate amount of a $5 \mathrm{M} \mathrm{NaCl}$ solution. The experiments were carried out in a 100-ml titration cell with a glass electrode and a calomel reference electrode saturated with $\mathrm{KCl}$ without any additional salt bridge. After an addition of acid or base the $\mathrm{pH}$ stabilized $(\Delta \mathrm{pH} /(0.5 \mathrm{~min})<0.01)$ quickly and $\mathrm{pH}$ was read within half a minute after the addition of acid or base preventing the dissolution of gibbsite.

In order to calculate from the titration data the change of surface charge, corrections had to be made for the amount of acid and base needed to change the $\mathrm{pH}$ of the solutions itself, by using activity coefficients. Titration experiments of blank $\mathrm{NaCl}$ solutions at the three salt levels used were performed to determine experimentally the activity coefficients involved. For the lowest two electrolyte levels $(0.005$ and $0.05 \mathrm{M} \mathrm{NaCl})$ the activity coefficients were nearly equal to the values calculated with the Debye-Hückel equation. The interposition of the curves was calculated from the change of the $\mathrm{pH}$ at the change of the electrolyte concentration taking into account the change of surface charge due to the increase of the electrolyte concentration.

Model calculations were carried out using a computer algorithm, partially based on the concepts of Westall \& Hohl (1980). The activity coefficients used were calculated according to the Debye-Hückel equation except for the highest salt level. In that case the coefficient was calculated with the mean salt method (Garrels \& Christ, 1965). Because of the small number of adjustable parameters $(\leqslant 2)$ the optimization could be obtained accurately by trial and error.

Finally, it is reported that the aluminium (hydr)oxide material was characterized by TEM, X-ray diffraction of a random oriented powder and TGA $\left(10^{\circ} \mathrm{C} / \mathrm{min}, \mathrm{T}_{\max }\right.$ $=1100{ }^{\circ} \mathrm{C}$ ). After five years of storage the BET surface area was determined by $\mathrm{N}_{2}$ gas adsorption.

\section{Results and discussion}

\section{Characterization of the adsorbent}

The X-ray diffraction analysis showed that no other aluminium (hydr)oxides were detectable than gibbsite. The water content determined with TGA by heating the sample up to $1100{ }^{\circ} \mathrm{C}$ was $1.42 \mathrm{~mol} / \mathrm{mol} \mathrm{Al}$ which is close to the theoretical water content of $1.5 \mathrm{~mol} / \mathrm{mol} \mathrm{Al}$. The BET surface area of the sample used was $19.8 \mathrm{~m}^{2} / \mathrm{g}$. No porosity could be observed from the BET data. The TEM observations indicated that only well developed more or less hexagonal crystals were present which were strongly developed in the $\mathrm{a}$ and $\mathrm{b}$ direction (Fig. 1). The particle size distribution of the gibbsite crystals $\left(n_{\mathrm{T}}=133\right)$ was calculated from these micrographs taking the mean half distance $(r)$ between opposing corners of the hexagonal crystals. This distribution is given in Fig. 2. 
T. HIEMSTRA, W. H. VAN RIEMSDIJK AND M. G. M. BRUGGENWERT

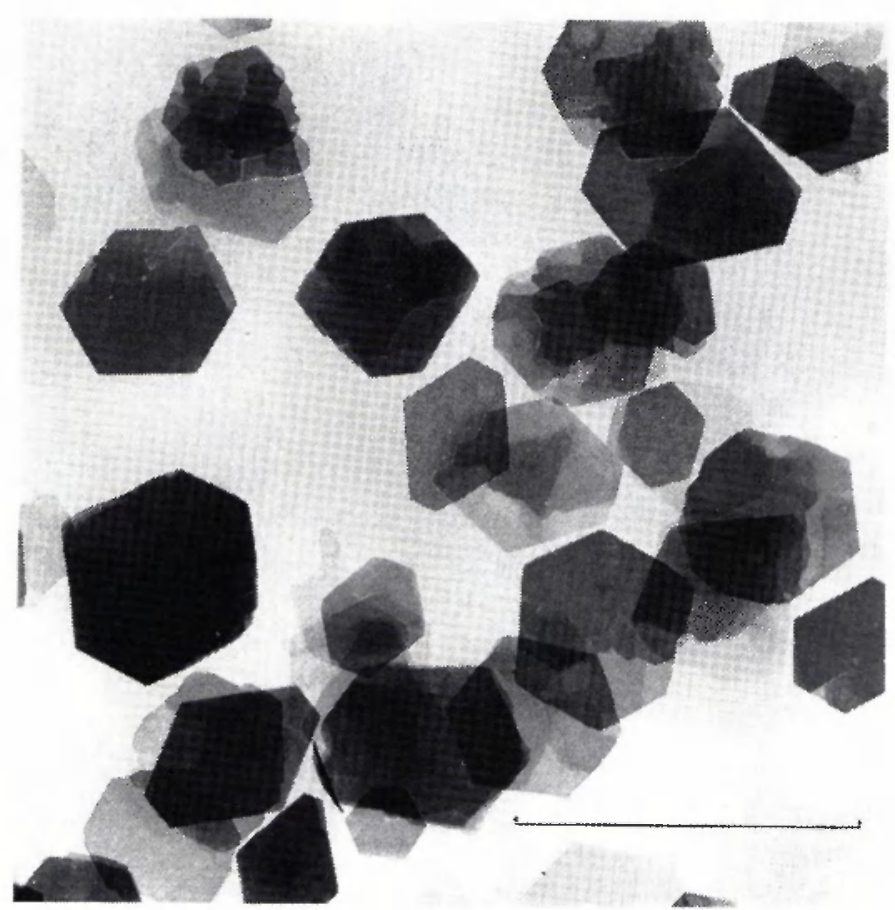

Fig. 1. Electron micrograph of the gibbsite used. The bar indicates a distance of $1 \mu \mathrm{m}$.

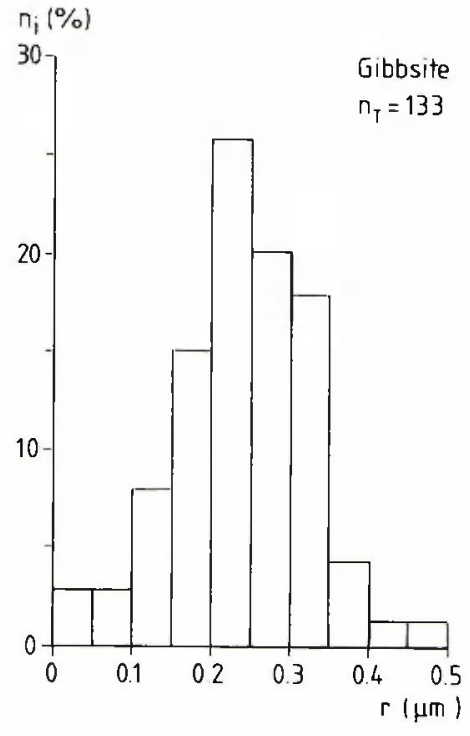

284
Fig. 2. The frequency distribution of the relative number $n_{\text {i }}$ of particles present in the indicated size classes, calculated from the measurements of 133 particles.

Netherlands Journal of Agricultural Science 35 (1987) 
From the particle size distribution the surface area of the edge sides can be calculated. For a hexagonal crystal it can be shown that the edge area $A_{\mathrm{e}}$ is equal to

$$
A_{\mathrm{e}}=4 /(\varrho r \sqrt{ } 3)
$$

where $Q$ is the density of the crystal. In order to calculate from the given distribution the edge area $A_{\mathrm{e}}$ some assumption must be made about the thickness $(h)$ of the crystals. For two different assumptions the edge area was calculated: (a) $h$ is constant over the entire range of $r$ and (b) $h$ is linearly related to $r$ which means that the form of the crystals is identical. These approximations lead to Eq. 2 and 3 respectively:

$$
\begin{aligned}
& A_{\mathrm{e}}=[4 / \varrho \sqrt{ } 3] \cdot\left[\Sigma\left(n_{\mathrm{i}} r_{\mathrm{i}}\right) / \Sigma\left(n_{\mathrm{i}} r_{\mathrm{i}}^{2}\right)\right] \\
& A_{\mathrm{e}}=[4 / \varrho \sqrt{ } 3] \cdot\left[\Sigma\left(n_{\mathrm{i}} r_{\mathrm{i}}^{2}\right) / \Sigma\left(n_{\mathrm{i}} r_{\mathrm{i}}^{3}\right)\right]
\end{aligned}
$$

A calculated edge area of 3.5 and $3.2 \mathrm{~m}^{2} / \mathrm{g}$ respectively was found with Eq. 2 and 3 . In the model calculations the edge area was set at $3.4 \mathrm{~m}^{2} / \mathrm{g}$ which is about $17 \%$ of the total available surface area. Van Riemsdijk \& Lyklema (1980) reported a somewhat smaller $A_{\mathrm{e}}$ value of $14 \%$ for similarly synthesized gibbsite by using TEM micrographs shadowed with Pt under a certain known angle. The difference is probably caused by a difference in the average particle size of both preparations.

At least two types of surface $\mathrm{OH}$ groups can be distinguished at the crystal faces of gibbsite crystals. The gibbsite structure is characterized by aluminium ions in hexa-coordination with hydroxyls. The $\mathrm{Al}^{3+}$ ions distribute their charge $(3+)$ over six surrounding hydroxyls neutralizing on the average half a unit charge per $\mathrm{Al}-\mathrm{OH}$ bond. The hydroxyls are bound by two aluminium ions, leaving one unit charge which is neutralized by the $\mathrm{H}^{+}$ion of the hydroxyl group. The $\mathrm{OH}$ groups at the planar side of an ideal crystal are therefore always doubly coordinated. At the edges of the mineral the situation is different. Most of the terminal $\mathrm{OH}$ groups are in pairs singly coordinated as is shown in Fig. 3. As indicated in Fig. 3 the $\mathrm{OH}$ ions are not laying completely in one plane. Based on the known crystal parameters (J.C.P.D.S.) the site density $N_{\mathrm{s}}$ of these singly coordinated ions has been calculated, leading to 9.6 sites per $\mathrm{nm}^{2}$ edge surface. The hydrolytic surface structures as described here are not restricted to metal hydroxides. Similarly different types of $\mathrm{OH}$ groups also cover the crystal faces of metal oxides such as hematite $\mathrm{Fe}_{2} \mathrm{O}_{3}$ (Parfitt, 1975) and $\mathrm{Al}_{2} \mathrm{O}_{3}$.

\section{Proton adsorption mechanism}

From the data given above one can conclude that the doubly coordinated $\mathrm{OH}$ ions are available in large excess at the gibbsite solid/solution interface. The overall surface charge as determined from titration experiments is positive at $\mathrm{pH}$ values below 10 indicating that these doubly coordinated surface $\mathrm{OH}$ groups are not dissociating to a noticeable extent in the $\mathrm{pH}$ range studied. With respect to the proton association reaction both singly and doubly coordinated groups can in principle react with 


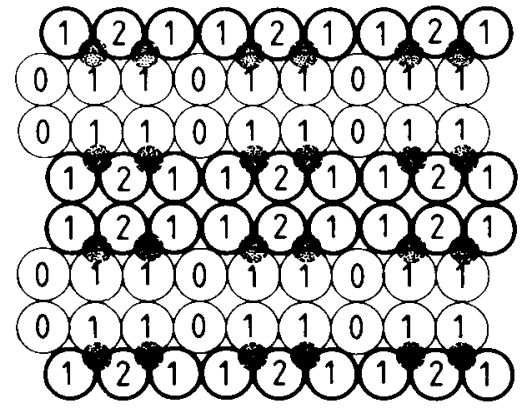

Fig. 3. Schematic representation of the interposition of surface groups at the edge face of a gibbsite crystal. The dark small circles represent the hexa-coordinated $\mathrm{Al}^{3+}$ ions, which are situated behind the hydroxyls, indicated by the larger circles. The bold circles are hydroxyls which are situated slightly more forward with respect to the other surface groups. The number $(1,2)$ in the circles indicates the coordination number with respect to Al. Non-coordinated water molecules are indicated with 0 .

$\mathrm{H}^{+}$. However from the crystallographic point of view one may assume that the reactivity of the $\mathrm{Al}-\mathrm{OH}$ is much higher than that of the $\mathrm{Al}_{2}-\mathrm{OH}$ groups due to the lower electropositive repulsion of one $\mathrm{Al}^{3+}$ ion. Pulver et al. (1984) also presumed for the bayerite $\left(\gamma-\mathrm{Al}(\mathrm{OH})_{3}\right)$ surface that only singly coordinated $\mathrm{OH}$ groups are reactive with respect to the uptake of extra protons.

\section{One-pK model}

As can be seen from Fig. 3 the singly coordinated $\mathrm{OH}$ groups are situated at the edges in pairs. The octahedral coordination of $\mathrm{Al}^{3+}$ implies that the two singly coordinated oxygens are together neutralized in the terminal plane by 3 protons at the pristine point of zero charge (PPZC). It means that the number of protons of a singly coordinated surface group will vacillate between one and two $\mathrm{H}^{+}$. Treating the singly coordinated $\mathrm{OH}$ groups as individual groups, therefore, leads to the following formal description of the local proton adsorption reaction at the surface (Bolt \& van Riemsdijk, 1982):

$$
\mathrm{SOH}^{1 / 2-}+\mathrm{H}_{\mathrm{s}}^{+} \rightleftharpoons ; \quad \mathrm{K}_{\mathrm{H}}
$$

in which $\mathrm{H}_{\mathrm{s}}^{+}$is the proton near the plane of adsorption and $K_{\mathrm{H}}$ the intrinsic proton association constant of the reaction specified. Introduction of the Boltzman accumulation factor $(\exp (-F \psi / R T))$ relating the local proton concentration to its equilibrium concentration in solution and taking logarithms, leads to the expression for $\log K_{\mathrm{H}}$ :

$$
\mathrm{pH}=\log K_{\mathrm{H}}-\log \left[\theta_{\mathrm{H}} /\left(1-\theta_{\mathrm{H}}\right)\right]-F \psi_{0} /(2.3 \mathrm{RT})
$$

in which $\psi_{0}$ is the potential at the surface. The fractional surface coverage with protons $\left(\theta_{\mathrm{H}}\right)$ is defined as $\left[\mathrm{SOH}_{2}^{1 / 2}\right] / N_{\mathrm{s}}$ in which $N_{\mathrm{s}}$ is the reactive site density $\left(\left[\mathrm{SOH}_{2}^{1 / 2-}\right]+\left[\mathrm{SOH}^{\mathrm{l}-}\right]\right)$ in $\mathrm{mol} / \mathrm{m}^{2}$. The surface charge density is given by:

$$
\sigma_{0}=N_{\mathrm{s}} \cdot F\left(\theta_{\mathrm{H}}-0.5\right)
$$

It follows from Eq. 4 that the PPZC corresponds to a situation where the surface 
density of $\mathrm{SOH}^{1 / 2-}$ and $\mathrm{SOH}_{2}^{1 / 2+}$ is equal $\left(\theta_{\mathrm{H}}=0.5\right)$. This result combined with Eq. 5 leads to the conclusion that:

$$
\log K_{\mathrm{H}}=\mathrm{PPZC}
$$

To relate finally the surface charge density $\sigma_{0}$ and the $\mathrm{pH}$ an electrostatic model is required, for instance the basic Stern model (BS) comprising an empty Stern layer and a flat diffuse double layer. On the basis of the BS theory the surface charge can be calculated from electrostatic reasoning with the following well-known formulas:

$$
\begin{aligned}
& \sigma_{0}=C\left(\psi_{0}-\psi_{\mathrm{d}}\right) \\
& \sigma_{0}=-\sigma_{\mathrm{d}}=-\left(8 \varepsilon_{\mathrm{r}} \varepsilon_{0} R T\right)^{1 / 2} \vee C_{0} \sinh \left(-F \psi_{\mathrm{d}} /(2 R T)\right)
\end{aligned}
$$

where $\psi_{\mathrm{d}}$ is in the basic Stern approximation the potential of the Stern layer (which has a capacitance $C$ ) and $C_{0}$ is the molar equilibrium concentration. The surface charge and the counter charge in the DDL are represented by $\sigma_{0}$ and $\sigma_{\mathrm{d}}$ respectively $\left(\sigma_{0}=-\sigma_{\mathrm{d}}\right)$.

Van Riemsdijk et al. $(1986,1987)$ successfully applied the one-pK model for description of the titration curves of $\mathrm{TiO}_{2}$, crystalline and amorphous iron (hydr)oxides.

\section{Titration data}

The acid/base titration data of gibbsite are presented as $\sigma_{0}$-pH in Figs. 4 and 5 using two different values for the reactive surface area. Unfortunately no indisputable $\mathrm{PZC}$ can be obtained from the titration data. Titrations to even higher $\mathrm{pH}$ values than 9.5 would probably not have resulted in a very accurate determination of this value because of the high uncertainty in this $\mathrm{pH}$ range due to the relatively large correction term that is involved in converting the raw titration data to the amount of protons adsorbed. At a $\mathrm{pH}$ of 9.5 the correction term mentioned is already about $50 \%$ of the total amount of base added between two points of the titration curve. The PZC is estimated to be about $10 \pm 0.5$ which value is slightly higher than values for gibbsite reported by Hingston (1972). The PPZC is set at 10 in the model calculations. It is noticed here that the titration curves hardly show any hysteresis indicating that the dissolution of aluminium can probably be neglected. Dissolution experiments at $\mathrm{pH} 4$ have confirmed that the rate of dissolution at that $\mathrm{pH}$ is still very low.

\section{Modeling proton adsorption curves}

Several approaches can be followed in modeling titration curves. A first approach could be to consider that all surface groups irrespective of their coordination react, as is frequently implicitly assumed for other metal oxides such as hematite and $\mathrm{TiO}_{2}$. It implies that the total BET surface area, - having a relatively high mean site density $\left(N_{\mathrm{s}}\right)$ of 14 sites $/ \mathrm{nm}^{2}$ - is reactive. This assumption in combination with the one-pK basic Stern model leads to a very good description of the data (Fig. 4). In 


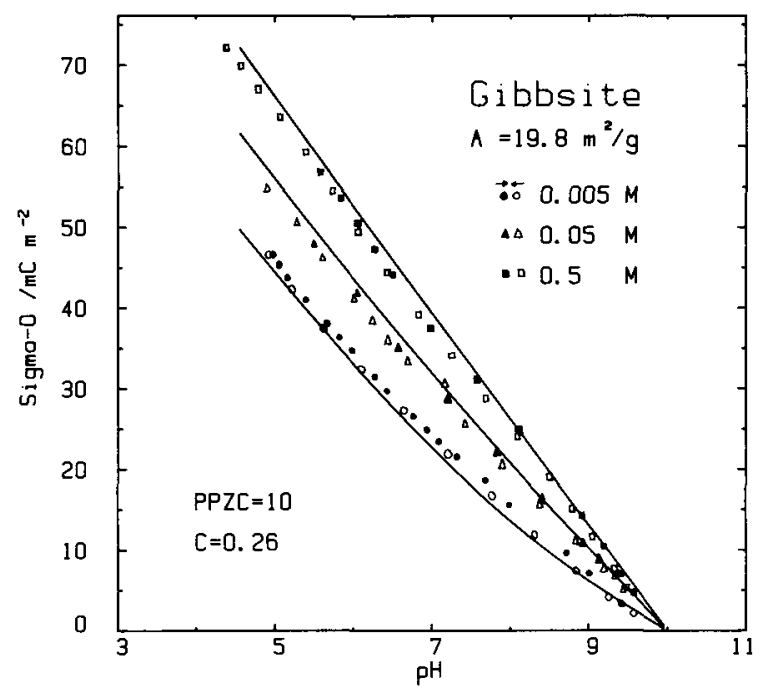

Fig. 4. The $\sigma_{0}-\mathrm{pH}$ data of gibbsite for three $\mathrm{NaCl}$ levels assuming a reactive surface area equal to the BET surface $\left(A=19.8 \mathrm{~m}^{2} / \mathrm{g}\right)$. The data points are indicated by open, respectively dark markers which indicate the data obtained from the forward respectively backward titration (with respectively acid and base). The solid lines are calculated using the parameter values $C=0.26 \mathrm{~F} / \mathrm{m}^{2}$ and $N_{\mathrm{s}}=14 \mathrm{sites} / \mathrm{nm}^{2}$.

this situation there is only one adjustable parameter, namely the capacitance $C$ of the empty Stern layer. However the fitted capacitance of the empty Stern layer is much lower $\left(C=0.26 \mathrm{~F} / \mathrm{m}^{2}\right)$ than what is usually found for metal (hydr)oxides (Westall \& Hohl, 1980; van Riemsdijk et al., 1986, 1987). On account of crystallographic considerations given in the preceding paragraphs a more realistic situation would be to consider that only the singly coordinated groups present at the edges are reactive $\left(N_{\mathrm{s}}=9.6 \mathrm{sites} / \mathrm{nm}^{2}\right.$ edge area). This means that the experimentally determined surface charge is now assumed to reside mainly at the edge surfaces leading to much higher local charge densities. The one-pK basic Stern model leads in this case to a relatively poor description of the data with a capacitance $C$ of about 3 to $4 \mathrm{~F} / \mathrm{m}^{2}$ (dashed line in Fig. 5). The predicted effect of the salt level is much higher than actually observed. Bolt \& van Riemsdijk (1982) showed that this influence can be decreased by forcing some counter ions to reside into the Stern layer. The assumption that the adsorption of 'indifferent' electrolyte ions such as $\mathrm{Na}^{+}$and $\mathrm{Cl}^{-}$ may occur even at the PPZC, is justified by recent experimental evidence (Smit \& Holten, 1980; Sprycha, 1983) and it can also be deduced from data for gibbsite presented by Hingston (1972).

The specific adsorption of electrolyte ions is modeled by extending the one-pK model with the following local equilibrium reactions for pair formation:

$$
\mathrm{SOH}^{1 / 2-}+\mathrm{Na}_{\mathrm{s}}^{+} \rightleftharpoons \mathrm{SOH}^{1 / 2-}-\mathrm{Na}^{+} ; \quad K_{\mathrm{c}}
$$

with 


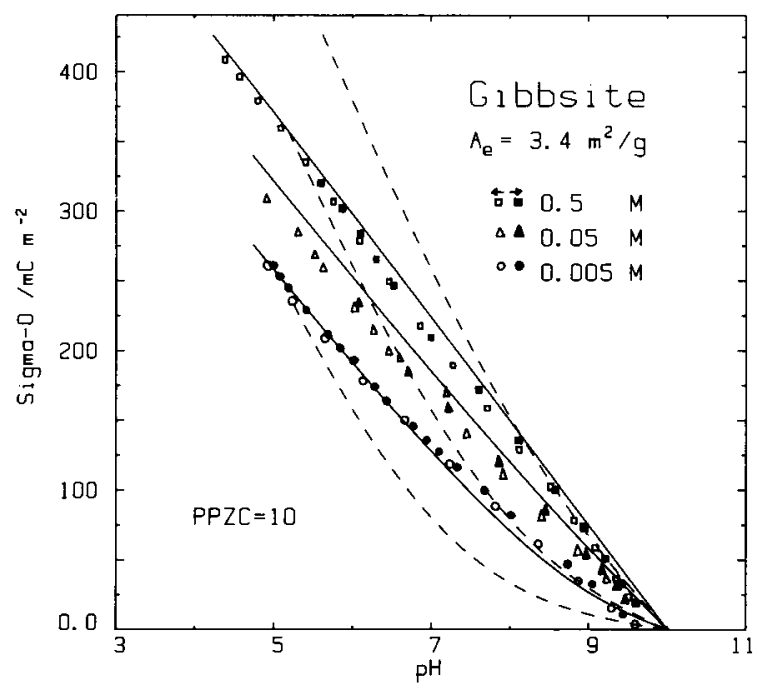

Fig. 5. The $\sigma_{0}-\mathrm{pH}$ data of gibbsite at three $\mathrm{NaCl}$ levels assuming a reactive surface area equal to the edge surface area $\left(A_{\mathrm{e}}=3.4 \mathrm{~m}^{2} / \mathrm{g}\right)$. The data points are indicated by open respectively black markers indicating the data obtained from respectively a forward and backward titration. The full lines are calculated curves using the one-pK Stern model extended with pair formation: $N_{\mathrm{s}}=9.6 \mathrm{sites} / \mathrm{nm}^{2}, \mathrm{p} K_{\mathrm{c}}=-0.1$, $C=1.40 \mathrm{~F} / \mathrm{m}^{2}$. The dashed lines are calculated acoording to the one-pK model without pair formation and $C=4 \mathrm{~F} / \mathrm{m}^{2}$.

$$
K_{\mathrm{c}}=\left[\mathrm{SOH}^{1 / 2-}-\mathrm{Na}^{+}\right]\left\{\left[\mathrm{SOH}^{1 / 2-}\right]\left(\mathrm{Na}^{+}\right) \exp \left(-F \psi_{\mathrm{d}} / R T\right)\right\}^{-1}
$$

and

$$
\mathrm{SOH}_{2}^{1 / 2+}+\mathrm{Cl}_{\mathrm{s}}^{-} \rightleftharpoons \mathrm{SOH}_{2}^{1 / 2+}-\mathrm{Cl}^{-} ; \quad K_{\mathrm{a}}
$$

with

$$
K_{\mathrm{a}}=\left[\mathrm{SOH}_{2}^{1 / 2+}-\mathrm{Cl}^{-}\left\{\left[\mathrm{SOH}_{2}^{1 / 2+}\right]\left(\mathrm{Cl}^{-}\right) \exp \left(+F \psi_{\mathrm{d}} / R T\right)\right\}^{-1}\right.
$$

in which $\mathrm{Na}_{\mathrm{s}}^{+}$and $\mathrm{Cl}_{\mathrm{s}}^{-}$are the sodium and chloride ions near the plane of adsorption (Stern layer), while $K_{\mathrm{c}}$ and $K_{\mathrm{a}}$ are intrinsic pair formation constants for the cation and anion respectively. In order to minimize the number of adjustable parameters and because of the lack of indication of an asymmetric titration behaviour it will be presumed that $\mathrm{p} K_{\mathrm{c}}=\mathrm{p} K_{\mathrm{a}}$. Now it is possible to describe the $\sigma_{0}-\mathrm{pH}$ curves based on $A_{\mathrm{e}}=3.4 \mathrm{~m}^{2} / \mathrm{g}$ relatively well (solid line in Fig. 5). The capacitance $C$ equals 1.40 $\mathrm{F} / \mathrm{m}^{2}$ which is in the order of values found for metal oxides such as $\mathrm{TiO}_{2}$ (van Riemsdijk et al., 1986), iron (hydr)oxides (van Riemsdijk et al., 1987) and $\mathrm{Al}_{2} \mathrm{O}_{3}$ (Westall \& Hohl, 1980).

The analysis of the data according to the last model has resulted in a set of reasonable parameter values describing the behaviour of the singly coordinated $\mathrm{Al}-\mathrm{OH}$ group at the gibbsite solid/solution interface. It is now of interest to elucidate as to 
how far the obtained parameters are applicable for the reaction of protons with Al$\mathrm{OH}$ groups at other aluminium (hydr)oxides and to examine the main reason causing differences in the charging behaviour of various aluminium (hydr)oxides.

The modeling of the related surface of $\mathrm{Al}_{2} \mathrm{O}_{3}$ by Westall \& Hohl (1980) resulted in a very low maximum charge density $\left(100 \mathrm{mC} / \mathrm{m}^{2}\right.$ determined from curve fitting by Westall \& Hohl, 1980). From this reported value the site density $N_{\mathrm{s}}$ (applicable for the one-pK model) can be calculated by taking into account the fact that one unit charge in the one-pK approach is realized with two proton adsorption sites in contrast to the two-pK model where it is often presumed that only one site is needed. $N_{\mathrm{s}}$ applicable for the one-pK model thus calculated equals $1.2 \mathrm{sites} / \mathrm{nm}^{2}$.

Westall \& Hohl (1980) implicitly assumed that the reactive sites are randomly distributed over the surface. The question arises whether the situation at the $\mathrm{Al}_{2} \mathrm{O}_{3}$ solid/solution interface is comparable with that of gibbsite, for example that only a fraction of the surface, with a high site density, is reactive. The data are fitted assuming that the total number of sites remains the same as given by Westall \& Hohl but that the distribution is no longer random but restricted to about $15 \%$ of the surface. The latter figure is calculated assuming $N_{\mathrm{s}}=8.5 \mathrm{sites} / \mathrm{nm}^{2}$ (Kummert \& Stumm, 1980) for the reactive surface. Model calculations based on this figure results only in a good fit of the $\sigma_{0}$ - $\mathrm{pH}$ curves if pair formation is assumed. The parameter values thus obtained are $C=7.5 \mathrm{~F} / \mathrm{m}^{2}$ and $\mathrm{p} K_{\mathrm{a}}=\mathrm{p} K_{\mathrm{c}}=-0.2$. The value of the Stern layer capacitance is very high and quite different from those reported for other metal oxides (van Riemsdijk et al., 1986, 1987). Similar modeling of other data of $\mathrm{Al}_{2} \mathrm{O}_{3}$ presented by Hohl \& Stumm (1976) and Kummert \& Stumm (1980) who determined the total amount of sites experimentally, shows also high values of $C$ if only a fraction of the surface is assumed to be reactive. These results suggest that for $\mathrm{Al}_{2} \mathrm{O}_{3}$ the site distribution is indeed random in contrast to that of the gibbsite solid/solution interface.

In order to assess as to how far the parameters for the charging characteristics of the various aluminium (hydr)oxide solid/solution interfaces are similar to those of gibbsite, it wil be assumed, as a first approach, that the pair formation constants of the background electrolyte ions with the singly coordinated surface aluminium-hydroxyl are equal to those obtained for gibbsite. The PPZC and $N_{\mathrm{s}}$ of the different aluminium oxides are taken as reported in the literature and summarized in Table 1. The data at the common $0.1 \mathrm{M}$ salt level are now fitted according to the one-pK Stern model, leaving only one parameter - the Stern layer capacitance $C$ - to be optimized. The results are shown in Table 1. It is nice to see how close the values are to each other suggesting that it is possible to describe the $\sigma_{0}$ - $\mathrm{pH}$ curves of all aluminium (hydr)oxides approximately with one set of parameters, provided the right $\mathbf{N}_{\mathrm{s}}$ values are taken. The slightly higher value of the capacitance of gibbsite could be due to an underestimation of the reactive surface area. Calculations show that if one accepts that $5-10 \%$ of the basal planes have structural defects, leading to the presence of singly coordinated ions, the fitted capacitance will be similar $(C=1.2$ $1.0 \mathrm{~F} / \mathrm{m}^{2}$ ) to the values found for the various $\mathrm{Al}_{2} \mathrm{O}_{3}$,

For further comparison the experimental data of the various aluminium oxides are presented in Fig. 6 together with three calculated curves for $N_{\mathrm{s}}=1.2,2.5$ and 
Table 1. The fitted capacitance $C$ of the Stern layer for several $\mathrm{Al}_{2} \mathrm{O}_{3}$ using the reported values as given in this table and the pair formation constant $\mathrm{p} K_{\mathrm{c}}=\mathrm{p} K_{\mathrm{a}}=-0.1$ found for gibbsite (this study).

\begin{tabular}{llccc}
\hline Author & Electrolyte & $\mathrm{PPZC}$ & $\begin{array}{l}N_{\mathrm{s}} \\
\left(\mathrm{nm}^{-2}\right)\end{array}$ & $\begin{array}{l}C \\
\left(\mathrm{~F} / \mathrm{m}^{2}\right)\end{array}$ \\
Huang \& Stumm (1973) & $0.1 \mathrm{M} \mathrm{NaCl}$ & 8.5 & 1.1 & 1.2 \\
Westall \& Hohl (1980) & $0.1 \mathrm{M} \mathrm{NaClO}_{4}$ & 8.3 & 1.2 & 1.1 \\
Hohl \& Stumm (1976) & $0.1 \mathrm{M} \mathrm{NaClO}_{4}$ & 8.3 & 2.6 & 1.0 \\
Kummert \& Stumm (1980) & $0.1 \mathrm{M} \mathrm{NaClO}_{4}$ & 8.7 & 2.4 & 1.2 \\
\hline
\end{tabular}

9.6 sites $/ \mathrm{nm}^{2}$. The dashed line $\left(N_{\mathrm{s}}=9.6 \mathrm{sites} / \mathrm{nm}^{2}\right)$ represents the charging behaviour of the surface groups situated on the edges of gibbsite. No titration data are available at the $0.1 \mathrm{M}$ salt level for the gibbsite used. The solid curves 1 and 2 are calculated for $N_{\mathrm{s}}=1.2$ and $2.5 \mathrm{sites} / \mathrm{nm}^{2}$ respectively. These values are equal or close to the values reported in the literature for $\mathrm{Al}_{2} \mathrm{O}_{3}$ (Table 1). The open markers in Fig. 6 indicate the data points of Hohl \& Stumm (1976) and Kummert \& Stumm (1980) $\left(N_{\mathrm{s}} \approx 2.5\right.$ sites $\left./ \mathrm{nm}^{2}\right)$, the dark markers indicate the data points of Huang \& Stumm $(1973)$ and Westall \& Hohl $(1980)\left(N_{\mathrm{s}} \approx 1.2\right.$ sites $\left./ \mathrm{nm}^{2}\right)$. Fig. 6 shows that the difference in proton adsorption behaviour between the various aluminium (hydr)oxides is mainly caused by differences in the site distribution and site densities of

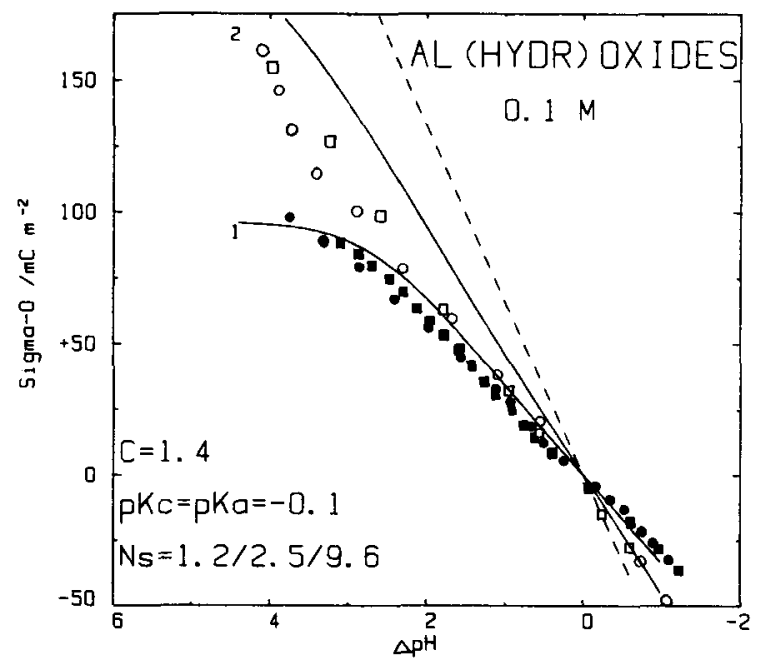

Fig. 6. Calculated $\sigma_{0}-\Delta \mathrm{pH}$ curves according to the one-pK Stern model for three site densities $\left[N_{\mathrm{s}}=1.2\right.$ and 2.5 sites $/ \mathrm{nm}^{2}$ (solid lines 1 and 2 respectively) and $9.6 \mathrm{sites} / \mathrm{nm}^{2}$ (dashed line)] with two adjustable parameters $C=1.4 \mathrm{~F} / \mathrm{m}^{2}$ and $\mathrm{p} K_{\mathrm{c}}=\mathrm{p} K_{\mathrm{a}}=-0.1\left(\Delta \mathrm{pH}=\mathrm{pH}_{0}-\mathrm{pH}\right)$.

The $\sigma_{0}-\Delta \mathrm{pH}$ data of aluminium oxides taken from literature are indicated separately. The dark markers represent data of aluminium oxides with reported site densities close to $N_{\mathrm{s}} \approx 1.2 \mathrm{sites} / \mathrm{nm}^{2}$ ( $\mathbf{\square}$ Huang \& Stumm, 1973; Westall \& Hohl, 1980). The open markers indicate the data of aluminium oxides with reported site densities close to $N_{\mathrm{s}} \approx 2.5 \mathrm{sites} / \mathrm{nm}^{2}$ ( $\bigcirc$ Hohl \& Stumm, 1976; $\square$ Kummert \& Stumm, 1980). 
the aluminium (hydr)oxides involved. It can be mentioned that by a slight adjustment of the individual values of $N_{\mathrm{s}}$ or the reactive surface area (for gibbsite) it is probably possible to get a very good description of all data with one set of values for the pair formation constants $K_{\mathrm{c}}=K_{\mathrm{a}}$ and Stern layer capacitance $C$ for all aluminium (hydr)oxides discussed here. It should be noticed that the similarity of the $\sigma_{0}$-pH curves of $\mathrm{Al}_{2} \mathrm{O}_{3}$ determined in $\mathrm{NaCl}$ (Huang \& Stumm 1973) and determined in Na$\mathrm{ClO}_{4}$ (Westall \& Hohl, 1980) (Fig. 6) both having approximately the same site density (Table 1), indicates that the anion pair formation constants for $\mathrm{Cl}$ and $\mathrm{ClO}_{4}$ are probably not very different. The similarity of the set of parameters for gibbsite as well as for $\mathrm{Al}_{2} \mathrm{O}_{3}$ suggests strongly that pair formation should be included in the description of the titration curves of all $\mathrm{Al}$ oxides although it is possible to describe the titration curves of $\mathrm{Al}_{2} \mathrm{O}_{3}$ at one salt level equally well without any pair formation as was also concluded by Westall \& Hohl (1980).

As described above the results indicate that the major factor responsible for the differences observed in the titration behaviour of aluminium (hydr)oxides, is a difference in the site density and site distribution. It is of interest to examine whether the presented literature values of $N_{\mathrm{s}}$ are reliable. Very low site densities $\left(N_{\mathrm{s}} \approx 1.2\right.$ sites/nm ${ }^{2}$ ) were reported by Huang \& Stumm (1973) and Westall \& Hohl (1980). The values were obtained graphically and by curve fitting respectively. Reliable values can in fact only be obtained if the $\sigma_{0}$ - $\mathrm{pH}$ curves are sensitive to changes of the parameter involved. As can be observed in Fig. 6 the $\sigma_{0}$-pH curves are bending at high $\Delta \mathrm{pH}$ values which can only be explained from the influence of the saturation of the surface with protons as described by the configuration term $\theta_{\mathrm{H}} /\left(1-\theta_{\mathrm{H}}\right)$ in Eq.5. For this reason the presented data by Huang \& Stumm (1973) and Westall \& Hohl (1980) are particularly sensitive to the adjustable parameter $N_{\mathrm{s}}$. Hohl \& Stumm (1976) and Kummert \& Stumm (1980) have reported the use of a back titration method to determine the value of $N_{\mathrm{s}}$. No details have been given about the method used. Besides a good fit of the data mentioned for $N_{\mathrm{s}}=2.5 \mathrm{sites} / \mathrm{nm}^{2}$ (Fig. 6) (assuming the suggested common values for the Stern layer capacitance and the pair formation constant), calculations indeed indicate that for the $N_{\mathrm{s}}$ value mentioned more than $90 \%$ of the sites can be titrated within the experimentally accessible $\mathrm{pH}$ range. It should be noticed that in general a simple back titration method can only be used if the site density is rather low as may be the case for $\mathrm{Al}_{2} \mathrm{O}_{3}$ but not for gibbsite.

\section{Conclusions}

- The results described above and the crystallographic considerations mentioned strongly suggest that the singly coordinated hydroxyls at the gibbsite and probably the $\mathrm{Al}_{2} \mathrm{O}_{3}$ surface are dominating the charging behaviour in the $\mathrm{pH}$ range mentioned.

- Analysis of the $\sigma_{0}$-pH curves of gibbsite suggest that pair formation of reactive surface sites with simple 1:1 electrolytes occurs.

- A coherent description of the charging behaviour of the various aluminium(hydr)oxides is possible with common values for $C, K_{\mathrm{c}}$ and $K_{\mathrm{a}}$ for all aluminium- 
(hydr)oxides.

- The distribution of reactive sites and the actual reactive site density are the main factors causing the differences in the charging behaviour of the various aluminium (hydr)oxides.

- A back titration method for the determination of the reactive site density can only be used successfull for metal oxides with a relatively low site density.

\section{Acknowledgement}

The first author wishes to thank Mr. Th. A. Vens for his accurate technical assistance. Thanks are also due to Mr. J. D. J. van Doesburg (Department of Soil Science and Geology) and Mr. P. A. I. Ehlert for their help in characterizing the gibbsite samples, and to Mr. A. J. Korteweg (Department of Physical and Colloid Chemistry) for the determination of the BET surface area.

\section{References}

Bolt, G. H. \& \& W. H. van Riemsdijk, 1982. Ion adsorption on inorganic variable charge constituents. In: G. H. Bolt (Ed.), Soil chemistry. B. Physicochemical models. 2nd ed., p. 459-504. Elsevier, Amsterdam.

Furrer, G. \& W. Stumm, 1986. The coordination chemistry of weathering. I. Dissolution kinetics of $\delta$ $\mathrm{Al}_{2} \mathrm{O}_{3}$ and $\mathrm{BeO}$. Geochimica Cosmochimica Acta 50: 1847-1860.

Gastuche, M. C. \& A. Herbillon, 1962. Etudes des gels d'alumine: cristallization en milieu désionisé. Bulletin de la Société Chimique de France 1: 1404-1412.

Garrels, R. M. \& C. L. Christ. 1965. Solutions, minerals and equilibria. Freeman, Cooper \& Company, San Francisco, 450 pp.

Hingston, F. J., A. M. Posner \& J. P. Quirk, 1972. Anion adsorption by goethite and gibbsite. I. Journal of Soil Science 23: 177-192.

Hohl, H. \& W. Stumm, 1976. The interaction of $\mathrm{Pb}^{2+}$ with hydrous $\gamma-\mathrm{Al}_{2} \mathrm{O}_{3}$. Journal of Colloid and Interface Science 55: 281-288.

Huang, C. P. \& W. Stumm, 1973. Specific adsorption on hydrous $\gamma-\mathrm{Al}_{2} \mathrm{O}_{3}$. Journal of Colloid and Interface Science 43: 409-420.

Kummert, R. \& W. Stumm, 1980. The surface complexation of organic acids on hydrous $\gamma-\mathrm{Al}_{2} \mathrm{O}_{3} . J o u r-$ nal of Colloid and Interface Science 75: 373-385.

Parfitt, R. L., R. J. Atkinson \& R. St. C. Smart, 1965. The mechanism of phosphate fixation by iron oxides. Soil Science Society of America Proceedings 39: 837-841.

Pulver, K.. P. W. Schindler, J. C. Westall \& R. Grauer, 1984. Kinetics and mechanism of dissolution of bayerite $\left(y-\mathrm{Al}(\mathrm{OH})_{3}\right)$ in $\mathrm{HNO}_{3}-\mathrm{HF}$ solutions at $298.2 \mathrm{~K}$. Journal of Colloid and Interface Science 101 : $5.54-564$.

Riemsdijk, W. H. van \& J. Lyklema, 1980. Reaction of phosphate with gibbsite $\left[\mathrm{Al}(\mathrm{OH})_{3}\right]$ beyond the adsorption maximum. Journal of Colloid and Interface Science 76: 55-66.

Riemsdijk, W. H. van, G. H. Bolt, L. K. Koopal \& J. Blaakmeer, 1986. Electrolyte adsorption on heterogeneous surfaces: adsorption models. Journal of Colloid and Interface Science 109: 219-228.

Riemsdijk, W. H. van, J. C. M. de Wit, L. K. Koopal \& G. H. Bolt, 1987. Metal ion adsorption on heterogeneous surfaces: adsorption models. Journal of Colloid and Interface Science 116: 511-522.

Smit. W. \& C. L. M. Holten, 1980. Zeta-potential and radiotracer adsorption measurements on EFG $\alpha$ $\mathrm{Al}_{2} \mathrm{O}_{3}$ single crystals in $\mathrm{NaBr}$ solutions. Journal of Colloid and Interface Science $78: 1-14$.

Sprycha, R., 1984. Surface charge and adsorption of background electrolyte ions at anatase/electrolyte interface. Journal of Colloid and Interface Colloid Science 102: 173-185.

Westall, J. \& H. Hohl, 1980. A comparison of electrostatic models for the oxide solution interface. Advances in Colloid and Interface Science 12: 265-294. 